\title{
Chitosan-Grafted Copolymers and Chitosan-Ligand Conjugates as Matrices for Pulmonary Drug Delivery
}

\author{
Fernanda Andrade, ${ }^{1}$ Francisco Goycoolea, ${ }^{2}$ Diego A. Chiappetta, ${ }^{3,4}$ José das Neves, ${ }^{1}$ \\ Alejandro Sosnik, ${ }^{3,4}$ and Bruno Sarmento ${ }^{1,5}$ \\ ${ }^{1}$ Department of Pharmaceutical Technology, Faculty of Pharmacy, University of Porto, Rua Aníbal Cunha 164, 4050-047 Porto, Portugal \\ ${ }^{2}$ Institut für Biologie und Biotechnologie der Pflanzen, Westfälische Wilhelms-Universtät Münster, Hindenburgplatz 55, \\ 48143 Münster, Germany \\ ${ }^{3}$ The Group of Biomaterials and Nanotechnology for Improved Medicines (BIONIMED), Department of Pharmaceutical Technology, \\ Faculty of Pharmacy and Biochemistry, University of Buenos Aires, 956 Junin Street, 6th Floor, 1113 Buenos Aires, Argentina \\ ${ }^{4}$ National Science Research Council (CONICET), C1033AAJ Buenos Aires, Argentina \\ ${ }^{5}$ CICS, Department of Pharmaceutical Sciences, Instituto Superior de Ciências da Saúde-Norte, Rua Central de Gandra 1317, \\ 4585-116 Gandra, Portugal
}

Correspondence should be addressed to Bruno Sarmento, bruno.sarmento@ff.up.pt

Received 28 April 2011; Accepted 21 July 2011

Academic Editor: Jianjun Li

Copyright ( $\odot 2011$ Fernanda Andrade et al. This is an open access article distributed under the Creative Commons Attribution License, which permits unrestricted use, distribution, and reproduction in any medium, provided the original work is properly cited.

Recently, much attention has been given to pulmonary drug delivery by means of nanosized systems to treat both local and systemic diseases. Among the different materials used for the production of nanocarriers, chitosan enjoys high popularity due to its inherent characteristics such as biocompatibility, biodegradability, and mucoadhesion, among others. Through the modification of chitosan chemical structure, either by the addition of new chemical groups or by the functionalization with ligands, it is possible to obtain derivatives with advantageous and specific characteristics for pulmonary administration. In this paper, we discuss the advantages of using chitosan for nanotechnology-based pulmonary delivery of drugs and summarize the most recent and promising modifications performed to the chitosan molecule in order to improve its characteristics.

\section{Introduction}

Alongside the successful market launch of different products over the last decades, a continuous effort to formulate delivery systems for the pulmonary administration of a wide variety of drugs has been extensively described in the literature $[1,2]$. The particular anatomical, physiological, and pathophysiological features of the respiratory tract pose enormous challenges that need to be overcome in order to obtain effective lung deposition, uniform distribution, in loco retention (main challenge is to circumvent mucocilliary clearance), and stability (particularly to enzymatic degradation) of therapeutic agents $[1,3]$.

Nevertheless, particular attention has been dedicated not only to drugs themselves but also to excipients required to improve the bioavailability of drugs administered pulmonarily.
In this context, excipients that could transiently enhance the absorption of drugs are on the spot. Chitosan, a polysaccharide with structural characteristics similar to glucosamines and obtained by the alkaline deacetylation of chitin, derived from the exoskeleton of crustaceans, is one of such appealing excipients.

The safety and tolerability of chitosan are synergistic characteristics towards its application in drug delivery by different administration routes. Despite the natural properties, some drawbacks are associated with the poor solubility at physiologic $\mathrm{pH}$ and the passive targeting effect. Thus, chemical modifications of chitosan by conjugating various functional groups allow the control of the hydrophilicity and the solubility at neutral and basic $\mathrm{pH}$ and open new opportunities to expand the application of this biopolymer. 
In this paper, we revise some of the most recent and promising modifications performed to chitosan with special focus on its employment in the pulmonary delivery of drugs.

\section{Advantages of Chitosan for Pulmonary Delivery of Drugs}

Chitosan possesses different beneficial properties that make it an attractive option for designing adequate dosage forms and advanced drug delivery systems to be administered to or through the lung. General advantages include the wellestablished biocompatibility and biodegradability of chitosan [4]. Moreover, antimicrobial [5] and antioxidant [6, 7] activities have been reported for different types of chitosan and derivatives, which can also be regarded as potentially useful for the development of pulmonary drug delivery systems. The processability of chitosan and several derivatives allow obtaining different types of systems (powders or wellstructured micro- and nanocarriers) that can be optimized in order to present optimal aerodynamic particle diameters for lung deposition and retention [8-11]. Also, the presence of reactive amine groups grants chitosan the chemical versatility for modification and functionalization (Figure 1) [12].

Chitosan is a cationic mucoadhesive polymer. The ability to establish ionic, hydrogen, and hydrophobic bonding with negatively charged chains of mucin [13], the structural component of mucus fluids, evidences its potential for increasing lung retention of drug carriers comprising chitosan. The mucoadhesive properties of the native polymer can be further increased by chemical modification. In particular, thiolation (i.e., attachment of side chains containing thiol groups) has been proved an interesting strategy for this last purpose [14]. In one recent study, Makhlof et al. [15] reported on the enhanced mucoadhesion of nanoparticles composed of thioglycolic acid-glycol chitosan, as compared to nanoparticles based on the nonthiolated polymer (i.e., glycol chitosan), after intratracheal administration to rats. More importantly, the increment in pulmonary mucoadhesion observed by these researchers was correlated with the greater bioavailability of calcitonin when this peptide was associated with nanoparticles. However, mucoadhesive properties of chitosan and derivatives may also be detrimental, since adhesion of delivery systems at the upper respiratory tract and airways can also occur, thus limiting the amount of carrier that effectively reaches the deep lung. Formulating scientists should keep this phenomenon in mind when developing chitosan-based systems.

Chitosan is able to enhance absorption of drugs by the paracellular route, in particular macromolecules, due to the transiently disruption of tight junctions (Figure 2) [16].

In order to confirm this effect in pulmonary drug delivery, Yamamoto et al. [17] performed in vivo experiments in guinea pigs by comparing the pulmonary absorption of different model drugs in solution (carboxyfluorescein and fluorescein isothiocyanate dextran with molecular weight (MW) varying from 4 to $70 \mathrm{kDa}$ ), either in the presence or absence of chitosan. Results showed significantly higher permeation for all the investigated model drugs in the presence

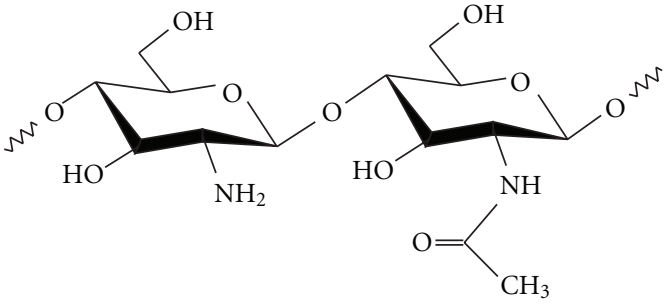

Figure 1: Chemical structure of chitosan, comprising $N$-acetyl-Dglucosamine (right) and D-glucosamine (left) units.

of chitosan, as assessed by blood drug levels. Absorption enhancement was higher for higher MW isothiocyanate dextran, which is mainly absorbed by the paracellular route, providing evidence for the mechanism of intercellular tight junction disruption.

Toxicological data on chitosan has been extensively reviewed and is regarded to be favorable when considering its use as a pharmaceutical excipient [4]. In the particular case of pulmonary drug delivery, in vitro cytotoxicity experiments were conducted for chitosan presenting different degrees of deacetylation and MW using human embryonic lung cells (L132 cells) [18]. Results revealed that chitosan presented $50 \%$ inhibitory concentration $\left(\mathrm{IC}_{50}\right)$ values higher than $1 \mathrm{mg} / \mathrm{mL}$. Studies have also been conducted for derivatives of chitosan or chitosan-based formulations intended for pulmonary administration. For instance, Grenha et al. [19] showed that chitosan nanoparticles obtained by ionotropic gelation with tripolyphosphate and entrapped in mannitol microparticles presented reduced toxicity (concentrations of up to $1.3 \mathrm{mg} / \mathrm{mL}$ of nanoparticles were tested) to adenocarcinoma epithelial lung cell lines (Calu-3 and A549). In another study conducted in A549 cells, stearic acid- $g$-chitosan oligosaccharide micelles presented an $\mathrm{IC}_{50}$ value of approximately $369 \mu \mathrm{g} / \mathrm{mL}$ [20]. However, chitosan and derivatives may also induce immune responses by lung cells/tissue. In an in vitro study, Calu-3 cells exposed to chitosan microparticles were able to elicit the release of inflammatory cytokines (IL-2 and IL-8) [21]. Florea et al. [22] performed in vivo studies in rats by administering intratracheally chitosan and two brands of $N$-trimethylated chitosan (TMC), presenting different degrees of substitution (20\% and 60\%). Histopathological analysis of lung tissue showed that chitosan elicited neutrophil infiltration and structural damage in the lung parenchyma; however, this effect may be attributable not to the inherent toxicity of chitosan but most probably to the physical obstruction of the bronchioles due to higher viscosity of the chitosan formulation, thus causing local asphyxiation. In the case of TMC, these effects were milder, which could be associated with lower viscosity when compared to chitosan. Comparable inflammatory effects were also observed in rats after the intratracheal administration of chitosan microparticles [23]. Moreover, the production of several proinflammatory cytokines has been observed for hydrophobically modified glycol-chitosan nanoparticles in vivo after intratracheal instillation in mice [24]. Even if generally regarded as detrimental, immune stimulation may 


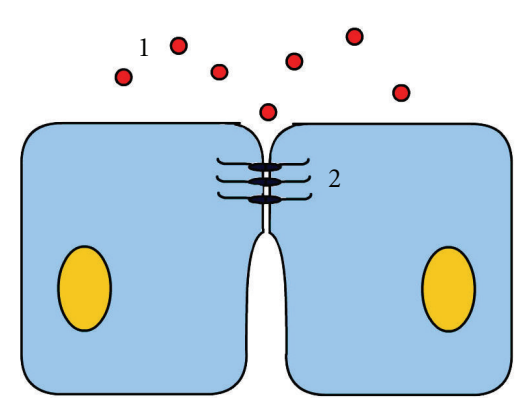

(a)

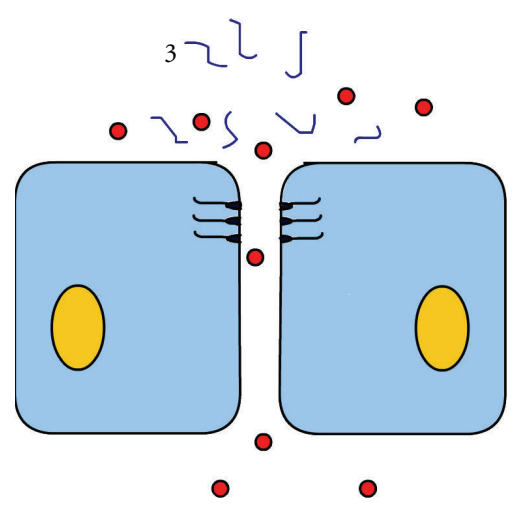

(b)

FIGURE 2: Effect of chitosan on the absorption of drugs by the paracellular route. (a) Normal epithelium. (b) Transient disruption of tight junctions by chitosan with enhancement of drug absorption. 1: represents the drug, 2: represents the tight junction, and 3: represents chitosan.

be a particularly interesting feature for vaccine development [25].

\section{Chitosan and Chitosan-Grafting Copolymers for Nanoparticle-Based Pulmonary Drug Delivery Systems}

The first nanoparticles with drug delivery purposes began in the late 1960s [26]. Nanoparticles are solid colloidal particles made of macromolecular materials ranging in size from 1 to $1000 \mathrm{~nm}$, although sometimes the term identifies particles in the 1 to $200 \mathrm{~nm}$ range, depending on the application field [27]. For pharmaceutical and medical applications, nanoparticles can be used therapeutically as carriers, either by dissolving, entrapping, or encapsulating the active substance (drug or biologically active material) or by adsorbing or attaching the active substance on the surface.

Different nanoparticles have been developed for pulmonary administration of various drugs to treat diseases such as tuberculosis (TB) [28-30] and other pulmonary infections $[31]$ and diseases $[31,32]$. Since this natural polymer offers remarkable advantages over other natural and synthetic polymeric carriers, in this section, we will focus on chitosangrafting-based polymeric nanoparticles as drug carriers.

3.1. Trimethyl Chitosan (TMC). Trimethylated chitosan (TMC) is a partially quaternized chitosan derivative that is freely soluble in aqueous solutions over a wide range of $\mathrm{pH}$ as compared to other chitosan salt derivatives (Figure 3). TMC is obtained by reductive methylation of chitosan using methyl iodide in the presence of a strong base (e.g., $\mathrm{NaOH}$ ) at $60^{\circ} \mathrm{C}[33,34]$. This soluble chitosan derivative has $\mathrm{mu}-$ coadhesive properties and displays excellent absorptionenhancing properties, even at neutral $\mathrm{pH}[35,36]$. This capability as enhancer is due to opening the tight junctions between adjacent epithelial cells through interactions between the protonated (positively charged) amino groups on the $\mathrm{C}-2$ position and the negatively charged sites on the cell membrane and/or in the tight junctions [37]; TMC has

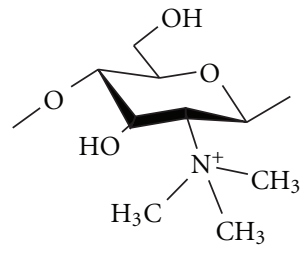

FIGURE 3: Chemical structure of trimethyl chitosan (showing the modification at the D-glucosamine unit).

positive charges, independently of the $\mathrm{pH}$, at all degrees of quaternization [38]. An increase in the degree of quaternization leads to increase of the permeation-enhancing effect of TMC [34].

TMC-based nanoparticles have consistently shown their feasibility for mucosal immunization. Studies have addressed oral vaccination against Helicobacter pylori using urease [39]. Intranasal administration of the influenza antigen elicited local and systemic immune responses in mice [40]. A similar approach was assessed with the tetanus toxoid by nasal instillation in mice [41]. TMC nanoparticles were loaded with FTIC ovalbumin, and their transport across the nasal epithelium of rat was studied [42]. A recent study has also shown that the delivery of the model antigen ovalbumin (OVA) to the cervical lymph nodes in a nanoconjugated form with TMC ( $\sim 30 \mathrm{~nm}$ diameter) was twice more effective than the nasal administration of ovalbumin-containing TMC nanoparticles with size of one order of magnitude greater $(\sim 300 \mathrm{~nm}$ diameter) [43]. In turn, synergistic effects of the TLR9 ligand CpG in TMC particles have been reported after nasal vaccination [44].

Florea et al. observed that $20 \%$ and $60 \%$ N-TMC (TMC20 and TMC60) enhanced the permeation of octreotide in vitro by 21-, 16-, and 30-fold. Also, the bioavailability was enhanced by 2.4-, 2.5-, and 3.9-fold, respectively. Cell viability and histology studies showed that the TMCs are safer than chitosan and that Calu-3 cell monolayers are a valuable model for predicting the paracellular transport kinetics in 
the airway epithelia. Taking into account these results, they sustain that cationic polysaccharides are promising enhancers for peptide drug absorption with prospect for sustainedrelease formulations [22]. Slutter et al. reported on the conjugation of an antigen, OVA, to TMC and the preparation of nanoparticles for subunit vaccination. The uptake of TMCOVA conjugates by dendritic cells was similar to the uptake of TMC/OVA nanoparticles and over 5-fold greater when compared to a solution of OVA and TMC. Conjugation of the antigen to TMC and TMC/OVA is therefore a viable strategy to increase the immunogenicity of subunit vaccines [45].

3.2. Carboxymethyl Chitosan (CMC). CMC is prepared by adding a carboxymethyl group in the structure of chitosan. This modification increases its solubility in neutral and basic solutions without affecting other important characteristics [46]. CMC is prepared by carboxymethylation of the hydroxyl and amine chitosan groups [47]. Different substitutions patterns can be obtained according to the reaction temperature used (Figure 4). At room temperature the O-substitution is favored, while at higher temperature the $\mathrm{N}$ substitution is the preferred pathway. Taking into account reaction conditions and reagents, different derivatives can be produced, that is, N-, O-, N,O-, or N,N-dicarboxymethyl chitosan [48].

CMC nanoparticles were prepared as carriers for some anticancer drugs. For example, Shi et al. used different kinds of CMC with various molecular weights and degrees of substitution to prepare nanoparticles through ionotropic gelification with calcium ions. These results showed the feasibility of CMC nanoparticles to entrap doxorubicin and the potential to deliver it following a controlled profile [49]. Anhitha et al. prepared curcumin-loaded O-CMC nanoparticles (curcumin-O-CMC Nps) as a novel carrier in cancer drug delivery applications. In L929, MCF-7, and PC-3 cell lines, the O-CMC NPs without drug showed no cytotoxicity, whereas curcumin and curcumin-O-CMC NPs resulted in considerable cell death. Cellular uptake was analyzed by fluorescence microscopy. Control cells without any exposure to NPs and cells incubated with O-CMC NPs showed no fluorescence. Conversely, cells incubated with curcumin$\mathrm{O}-\mathrm{CMC}$ NPs displayed green fluorescence, confirming the internalization of the particles [46]. In another work, tea polyphenols (TPs) were loaded into carboxymethyl chitosan and chitosan hydrochloride [50]. In vitro studies showed that TPs were controlled released from nanoparticles in PBS at $\mathrm{pH}$ 7.4. In addition, the cell apoptosis rate was increased from $30 \%$ after $24 \mathrm{~h}$ to $62 \%$ at the end of $72 \mathrm{~h}$, induced by loaded nanoparticles.

CMC-based nanoparticles of varying average size (40$400 \mathrm{~nm}$ diameter) were developed for intranasal immunization [41]. An interesting finding of this study was that TMCMCC composite nanoparticles obtained by electrostatic complexation of the two polymers with a positive surface charge exhibited higher immune responses when compared to chitosan, TMC, and MCC nanoparticles.

Li et al. prepared nanoparticles with oleoyl-carboxymethyl chitosan encapsulating rifampicin as drug delivery systems
[51]. These nanoparticles were not tested for any specific route of administration. But their pulmonary administration could be a possibility to treat tuberculosis. Therefore, it is necessary to carry out studies to test the feasibility of these NPs as inhaled drug delivery systems.

3.3. N-Succinyl-Chitosan (NSC). NSC is a chitosan derivative obtained by the incorporation of succinyl moieties into the $\mathrm{N}$-terminal group of the glucosamine units (Figure 5) [52]. Like other derivatives, NSC displays good water solubility in a broad $\mathrm{pH}$ range, and it is considered biocompatible both in vitro and in vivo. NSC was initially developed as a wound dressing material combined with collagen. It is also recognized as an excellent cosmetic ingredient (Moistfine liquid, INCI name Chitosan Succinamide).

Some authors have used this chitosan derivative to prepare anticancer-drug-loaded NPs. For example, Hou et al. synthesized a new NSC derivative by means of microwave irradiation. They entrapped successfully hydroxycamptothecin (HCPT) into the NSC nanoparticles and observed tumor targeting and significant suppression of tumor growth after s.c. injection (close to the tumor) in mice bearing S180 sarcoma tumor [53]. Yan et al. prepared similar nanoparticles loaded with 5-fluorouracil (5-FU) [54]. They evaluated biodistribution and tumor targeting after i.v. administration in Sarcoma 180-bearing mice. The 5-FU-loaded NPs were biodistributed mainly in the tumor and liver, being found small quantities in kidney and spleen [54]. Luo et al. evaluated antitumor effects of NSC nanoparticles (NSCNPs) without drugs in K562 cells [55]. The results revealed that NSCNP could inhibit the proliferation of $\mathrm{K} 562$ with an $\mathrm{IC}_{50}$ of $37.78,14.26,10.93$, and $9.78 \mathrm{vg} / \mathrm{mL}$ at $12,24,36$, and $48 \mathrm{~h}$, respectively. According to a cytomorphology study and the analysis of DNA fragments, the antitumor effect of NSCNP is achieved by necrosis and apoptosis induction in K562 cells.

3.4. PEGylated Chitosan. Grafting of hydrophilic polymers such as PEG onto chitosan is a well-known strategy to improve the solubility and biocompatibility of chitosan as well as to achieve lower recognition by the host immune system and increased blood circulation time (Figure 6) [56]. These PEG chains create a barrier layer to prevent the adhesion of opsonins present in the blood, so that the particles can be "invisible" to phagocytic cells.

Due to the advantages that PEG confers to chitosan, chitosan-g-PEG copolymer has been prepared and utilized to develop various types of nanocarriers for transmucosal drug delivery. Chitosan-g-PEG nanoparticles have been prepared by ionotropic gelation with TPP [57]. This system displayed a high association efficiency $(>78.6 \%)$ leading to insulin loading values as high as $38.6 \%$. Results of in vivo studies after intranasal administration to healthy rabbits showed that the plasma glucose levels fell sharply and remained at a low concentration for, at most, $2-3 \mathrm{~h}$ and returned to baseline after $5 \mathrm{~h}$. Other studies have shown that, apart from the reduction of the cytotoxicity, PEGylation of TMC led to improved colloidal stability of polyplexes and significantly increased 


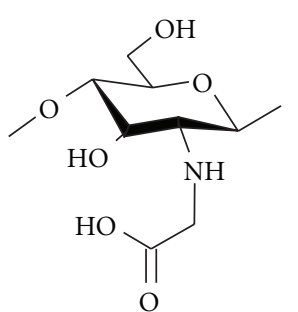

(1)

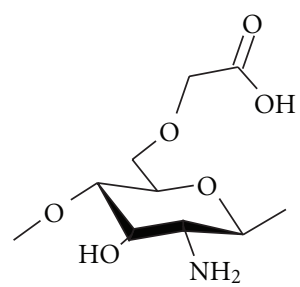

(3)

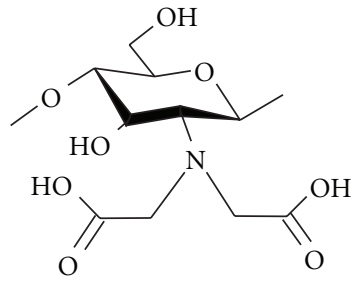

$(2)$

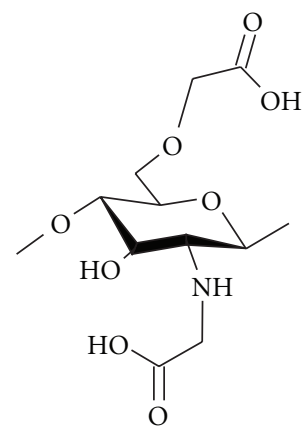

(4)

Figure 4: Chemical structure of different types of carboxymethyl chitosan (CMC): (1) N-CMC, (2) N,N-CMC, (3) O-CMC, and (3) N,OCMC (showing the modification at the D-glucosamine unit).

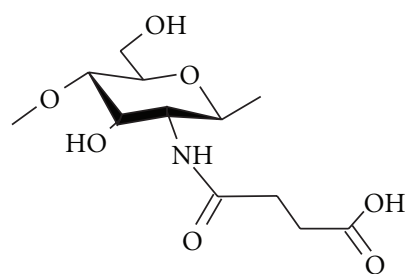

FIGURE 5: Chemical structure of $N$-succinyl-chitosan (showing the modification at the D-glucosamine unit).
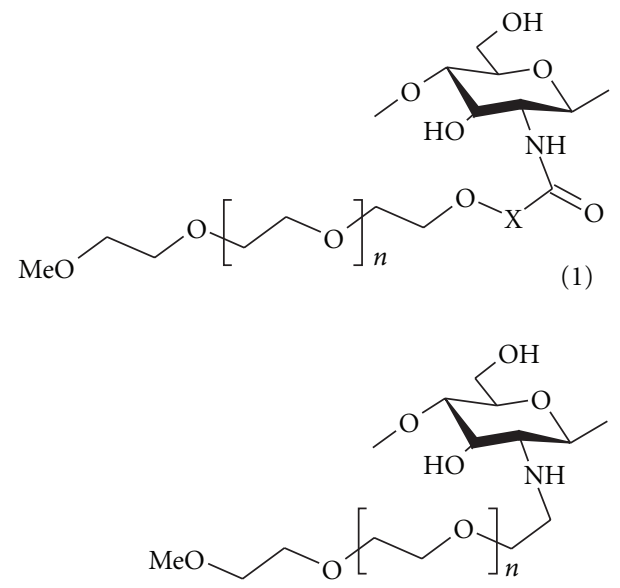

(2)

FIGURE 6: PEG- $g$-chitosan as obtained by the two most commonly used synthetic routes: (1) reaction with an active ester derivative and (2) reductive amination. X: linker. cellular uptake compared to unmodified TMC [58]. These improvements resulted in a significant, up to 10 -fold, increase of transfection efficiency in NIH/3T3, L929, and MeWo cells.

Mao et al. prepared chitosan-DNA nanoparticles using a complex coacervation process [59]. They conjugated PEG on the nanoparticles and observed that the clearance of the PEGylated nanoparticles in male AKR/J mice (6-8 weeks) following intravenous administration was slower than that of unmodified nanoparticles at $15 \mathrm{~min}$, with higher depositions in kidney and liver [59]. Other authors developed a functional nanoparticulate carrier for DNA transfection in asialoglycoprotein receptor overexpressed in HepG2 cells. For this, they grafted a methoxy PEG (MPEG) and a receptor ligand, lactobionic acid (LA) in chitosan [60]. They observed that the system with ligand chitosan-(O-MPEG)-(N-LA) showed better transfection efficiency $(45.3 \%)$ than ligandfree chitosan-(O-MPEG) (19.8\%).

3.5. Thiolated Chitosan. Thiol modifications to chitosan and nanoparticles derived from it have been aimed to localize a drug delivery system at a given target site (Figure 7). Recently, it was documented that thiolated chitosan has strong mucoadhesive properties ascribed to the formation of disulfide bonds with cysteine-rich domains of mucus glycoproteins, leading to an improvement in mucoadhesion of up to 140 -fold when compared to unmodified chitosan [61]. Insulin-loaded nanoparticles prepared with chitosan-Nacetyl-L-cysteine were found to improve the systemic absorption of insulin after nasal administration [62]. Although the exact mechanism for the enhanced effectiveness of this 


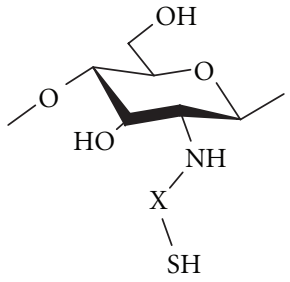

$(1)$

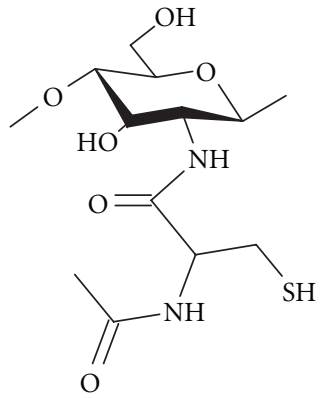

(2)
Figure 7: Thiolated chitosan: (1) general structure of thiolated chitosan as modified by an -SH group and (2) chitosan- $N$-acetylcysteine (showing the modification at the $\mathrm{D}$-glucosamine unit). X: linker.

system remains unclear, it was speculated that the mucoadhesive and permeation-enhancing properties based on disulfide bond "anchorage" increase the accessibility of insulin molecules to the epithelial membrane and, hence, facilitates the absorption of the protein across the nasal epithelium.

\section{Chitosan-Based Polymeric Micelles for Pulmonary Drug Delivery}

Micelles are spherical nanosized colloidal dispersions with a hydrophobic core and hydrophilic shell, composed by am-phiphilic molecules which self-assembly under certain concentration and temperature conditions (Figure 8). The concentration and the temperature above which the monomers turn in micelles are called critical micelle concentration (CMC) and critical micellization temperature (CMT), respectively [63]. The self-assembly of amphiphilic molecules in water is driven by a gain in entropy of the solvent molecules and a decrease of free energy in the system as the hydrophobic components withdraw from the aqueous media [64]. Two forces are involved in the micelle formation, an attractive force that leads to the association of molecules and a repulsive force that prevents unlimited growth of the micelles [65]. Micelles can be used as drug delivery systems, especially for poorly water-soluble drugs that are incorporated into the micelle core. Like liposomes, polymeric micelles allow the encapsulation of drugs with different polarities. Water-soluble drugs are adsorbed on the micelle surface, and drugs with intermediate polarity are distributed along the amphiphilic molecules [66]. However, they are more stable than liposomes. Furthermore, due to its general small size, micelles have the ability to penetrate tissues, showing also a high encapsulation efficiency and possibility of sterilization by filtration $[63,66,67]$.

Recently, much attention has been given to polymeric micelles formed by lipid polymer or block copolymers, generally di- and triblock copolymers, as drug delivery systems. Compared to micelles prepared from conventional detergents, polymeric micelles present a lower CMC value, making them more physically stable, both in vitro and in vivo,

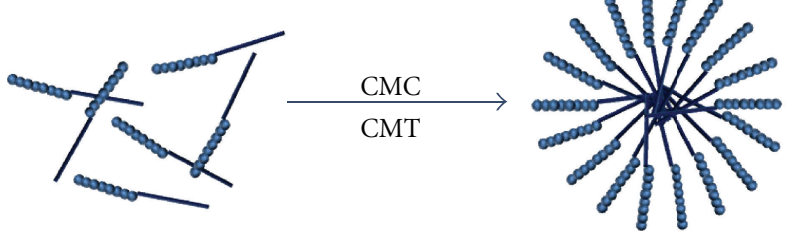

FIGURE 8: Formation of micelles by self-assembly of polymer monomers above critical micelle concentration (CMC) and critical micellization temperature (CMT).

even under dilutions to final concentration below the CMC [68]. Many studies have been published in the last years regarding the use of polymeric micelles as solubilization agents and bioavailability enhancers of different drugs, with emphasis on poorly soluble anticancer drugs [69-73]. They have also been studied as carriers of genetic material [74] and diagnostic agents [75]. Due to its size, generally lower than $200 \mathrm{~nm}$, and hydrophilic surface, micelles are poorly recognized by the reticuloendothelial system (RES) and present long circulation times in bloodstream with enhanced permeability and retention effects (EPR effect) at solid tumor sites or another areas with leaky vasculature such infarcts, infections, and inflammations, for passive targeting $[76,77]$. It is also possible to promote the targeting of drugs to specific organs and tissues using stimuli-responsive micelles [77-79] or modulating the micellar surface with active-targeting ligands $[77,80]$. By sharing some structural and functional features with natural transport systems, for example, virus and lipoproteins, polymeric micelles can be a useful strategy to solve the problem of drug resistance [81].

Different polymeric micelles have been developed, in the last years, for pulmonary administration of various drugs to treat different diseases such as cancer [82], inflammation conditions [83], and pulmonary infections [84-86]. They have been also studied as carriers of genetic material to treat cystic fibrosis [87]. In this section, we will focus on chitosanbased polymeric micelles as drug carriers.

4.1. Chitosan-Based Micelles. Due to its cationic nature, chitosan can be complexed with negatively charged DNA and be used as nonviral vector for gene therapy. $\mathrm{Hu}$ and coworkers synthesized stearic acid- (SA-) grafted chitosan oligosaccharide $(\mathrm{CSO})$ in order to produce polymeric micelles to delivery pDNA (pEGFP-C1) [88]. The SA-CSO/DNA micelles efficiently protected the condensed DNA from enzymatic degradation by DNAse I and presented lower cytotoxicity and comparable transfection efficiency in A549 cells compared to Lipofectamine 2000 [88], making these micelles a promising gene delivery system in the treatment of pulmonary diseases. The same research group developed SACSO micelles for the delivery of drugs like paclitaxel [89], doxorubicin [90, 91], and proteins [92]. The encapsulation of doxorubicin in SA-CSO micelles resulted in higher uptake and accumulation by $\mathrm{A} 549$ cells and a decrease in the $\mathrm{IC}_{50}$ [20]. Recently, SA-CSO micelles were developed by another 
research group, for the pulmonary administration of amphotericin B (AmB) [93]. The local administration of AmB to treat invasive pulmonary fungal infections, present in some patients receiving immune suppressive treatments, avoids the systemic side effects and improves the bioavailability of the drug [94]. After encapsulation into micelles, AmB presents the same antifungal activity of Fungizone but lower toxicity [93], a phenomenon intimately related to its aggregation state [95]. The micelles possessed positive charges with mean diameters between 100 and $250 \mathrm{~nm}$ and were efficiently nebulized using an Air-jet nebulizer presenting up to $52 \%$ of fine particle fraction, making them a suitable choice for pulmonary delivery of AmB [93].

In the field of block copolymers, Liu and coworkers developed an triblock copolymer consisting of poly ( $\varepsilon$-caprolactone)- $b$-chitooligosaccharide- $b$-poly(ethylene glycol) (PCLb-COS-b-PEG) for delivery of drugs, using doxorubicin as model drug [96]. The obtained polymer presents the capacity to form micelles with encapsulation efficiency of doxorubicin close to $50 \%$. Genipin after crosslinking did not affect the macroscopic characteristics of the micelles but delayed the in vitro release of doxorubicin from the micellar reservoir [96]. Similar results were obtained by Chen et al. using chitosanpoly( $\varepsilon$-caprolactone)-poly(ethylene glycol) to encapsulate paclitaxel and rutin with glutaraldehyde after crosslinking [97]. Wu and co-workers also synthesized chitosan-based copolymers for drug delivery [98]. Polylactide- (PLA-) chitosan copolymers with different molar ratios were developed and characterized. Rifampicin was used as lipophilic drug model to be encapsulated. As PLA molar ratio increased, the micelle size and drug-loading content increased, and the rifampicin release rate decreased [98]. The present systems were not tested for any specific route of administration.

Besides the creation of lipid-chitosan and polymer-chitosan conjugates, it is also possible to produce chitosan derivatives with amphiphilic characteristics that may self-assemble in aqueous environment and form polymeric micelles [99-101]. Zhang and co-workers synthesized different chitosan derivatives composed by long-chain alkyl groups as hydrophobic moieties and sulfated groups as hydrophilic moieties to delivery of paclitaxel [102]. Between the different derivatives, $\mathrm{N}$-octyl-O-sulfate chitosan presented the best results in terms of solubilization of paclitaxel [102]. Paclitaxel-loaded micelles prepared with $\mathrm{N}$-octyl-O-sulfate chitosan had high drug-loading capacity and encapsulation efficiency, were shown to be safe for intravenous injection, and presented similar antitumor efficacy as Taxol, but significantly reduced toxicity and improved bioavailability [103]. They also synthesized N-alkyl-N-trimethyl chitosan derivatives to deliver 10-hydroxycamptothecin. The best results in terms of encapsulation efficiency, stability, release behavior, and pharmacokinetic properties were obtained with $\mathrm{N}$ octyl-N-trimethyl chitosan (degree of octyl and trimethyl substitution is $8 \%$ and 54\%, resp.) [104]. Another research group studied the feasibility of $\mathrm{N}$-succinyl-N-octyl chitosan as delivery system of doxorubicin [105]. Although these systems have been tested for intravenous administration, they present antitumor efficacy against lung cancer cell lines such as Lewis lung cancer cells [103] and A549 cells [103, 105].
Their pulmonary administration could be a possibility to treat locally lung cancer; however, studies are required to access its feasibility as inhaled drug delivery systems.

Chitosan-based polymeric micelles have also been developed as drug delivery systems for other routes of administration than pulmonary, with emphasis on intravenous administration of paclitaxel. Examples are the N-mPEG-N-octyl$\mathrm{O}$-sulfate chitosan micelles produced by $\mathrm{Qu}$ and co-workers [106], the N-lauryl-carboxymethyl-chitosan micelles developed by Miwa et al. [107], and the N-octyl-N-(2-carboxylcyclohexamethenyl) chitosan micelles produced by Liu and co-workers [108]. Other chitosan-based micelles have been developed such as the doxorubicin-loaded linoleic acidgrafted chitosan oligosaccharide micelles produced by Du et al. for intercellular antitumor drug delivery to drug resistance tumor cells $[109,110]$ or the methoxy poly(ethylene glycol)grafted chitosan micelles for delivery of methotrexate to treat colon carcinoma $[111,112]$.

\section{Chitosan-Ligand Conjugates for Nanoparticle-Based Active Target Drug Delivery Systems}

As discussed in previous sections, chitosan is an ideal natural polymer for the design and development of drug delivery systems structured at micro- and nanoscopic scales. Particularly, its mucoadhesiveness [113, 114], biocompatibility $[115,116]$, and capacity to promote the absorption of poorly absorbable macromolecules across epithelial barriers by transient widening of cell tight junctions thus modifying the parallel transport [117-120] have been exploited in the development of nanocarrier systems for transmucosal delivery. A recognized feature of chitosan-based nanostructured systems is their capacity to protect sensitive therapeutic macromolecules against degradation and their ability to overcome mucosal barriers. As a consequence, their application has been centered particularly in noninvasive routes of administration including transmucosal administration of proteins [121-125] and genetic material [126-130].

The capacity of chitosan to undergo multiple chemical modifications has been exploited to increase the active targeting of chitosan-based nanocarriers particularly for protein and genetic material delivery towards specific cells [126, 131]. The modifications have comprised from derivatization with small functional groups or substructures (e.g., thiolated derivatives, grafted PEG) to conjugation with biologically active ligands such as carbohydrates (e.g., galactose, mannose) or specific ligands such as folate, transferrin, or KNOB viral protein. Nanocarrier systems of this kind with improved biological and biopharmaceutical performance have been the subject of active research in the past decade or so, as discussed, with reference to specific systems, in the following sections.

5.1. Conjugation of Sugar Ligands. Strategies to improve the targeting potential of chitosan have addressed its functionalization with sugar moieties, mostly with D-galactose and D-mannose. Galactose groups were chemically bound to 
chitosan aiming to achieve liver target delivery, while dextran was grafted to enhance the stability of the complex in aqueous media. The system was found efficient to transfect liver cells expressing asialoglycoprotein receptor (ASGRr), which specifically recognizes the galactose ligands on modified chitosan [132]. Galactosylated chitosan-graft-PEG (GCP) was developed for the same purpose. GCP-DNA complexes were found to be stable due to hydrophobic shielding by PEG and increased the stability against DNAse degradation. This system was found to enhance the transfection of HepG2 cells having ASGRr, thus indicating that galactosylated chitosan is an effective hepatocyte-targeted gene carrier [132]. This same system was tested in vivo by a different group. Glycoconjugated chitosan was designed for ASGRr-directed delivery to liver parenchymal cells. It was found that this system has the potential to be a vector for targeting to Kupffer cells in vivo. Other chitosan glycoconjugates have incorporated lactose to develop gene nanocarriers. HeLa cells were effectively transfected by this nanocarrier system, but neither HepG2 nor BNL CL2 cells. TEM evidence was consistent with the proposal that the nanocomplexes were internalized by HeLa cells and located inside endocytotic vesicles and endosome-like compartments [133]. In turn, efforts have been made to target mannose receptors on dendritic cells residing in tumors; hence, chitosan has been functionalized with mannose. Using these nanoparticles in the delivery of a plasmid encoding IL-12 resulted in enhanced IL-12 gene transfer efficiency, suppressed tumour growth and angiogenesis in the carcinoma $\mathrm{BALB} / \mathrm{c}$ mouse model [134]. A trisaccharide branch was attached onto chitosan chain in order to target lectins on the cell surface in lung tissues [135]. This modification increased the carrier uptake and transfection efficiencies in various in vitro assays as well as in mouse lung tissue as recently reviewed elsewhere [136].

5.2. Conjugation of Folate. Folic acid (FA) is appealing as a ligand for targeting cell membrane and allowing nanoparticle endocytosis via the folate receptor (FR) for higher transfection yields. Importantly, the high affinity of folate to bind its receptor ( $1 \mathrm{nM})$ [137] and folate small size allows its use for specific cell targeting. Moreover, the ability of FA to bind its receptor to allow endocytosis is not altered by covalent conjugation of small molecules [138]. Folate receptor (FR) is over-expressed on many human cancer cell surfaces, and the nonepithelial isoform of FR (FRb) is expressed on activated synovial macrophages present in large numbers in arthritic joints [139]. Hence, folate conjugation to the surface of chitosan and chitosan-derivatives-based nanoparticles has been one of the actively studied strategies to vectorize drugs over the past few years [140-149]. These systems have been developed with a view to achieve targeting effect in the delivery of cytostatic drugs to tumor cells, genetic material, or antiarthritis therapies and also for diagnostic and imaging purposes. To this end, the majority of in vitro studies have been conducted in various types of cell lines well known to overexpress the human folate receptors (FRa and FLRb), such as HeLa [145], HT29 [143], Caco-2 [143], B16F1 [150], KB [151, 152], HepG-2 [153], and SKOV3 [141, 154] cells.
The evidence from most of these studies is consistent to indicate that the folic acid modification promotes the uptake of nanoparticles by FR-positive tumor cell lines most likely via receptor-mediated endocytosis but has little impact on other cells without FR [155]. Results of transfection studies showed that folate-chitosan-based nanoparticles enhanced the reporter gene expression against a cell line overexpressing FR (SKOV3 cells) compared to an FR-deficient cell line (A549 cells) and did not induce obvious cytotoxicity against HEK 293 cells [154]. In turn, NPs made out of folategrafted chitosan were produced to transfect interleukin-1 receptor antagonist (IL-1Ra) in synovial mononuclear cells and CD14+ cells via the targeting of the folate receptor-b [156]. Compared to unmodified chitosan or naked DNA, this system allowed for an increase in IL-1Ra expression combined with a diminution of cytotoxicity in vitro and reinforced protection against inflammation and abnormal bone metabolism in vivo.

5.3. Conjugation of Protein Ligands. Proteins, such as transferrin and viral KNOB, have been conjugated at the surface of chitosan-based nanoparticles intended for DNA delivery, as a strategy to achieve active targeting and thus high transfection efficiency $[59,157]$. The transferrin receptor (TfR) is found in many mammalian cells, responsible for iron import to cells, and it is known to enhance the transcytosis of viral vector $[158,159]$. Transferrin (Tf) or antibodies against TfR were conjugated to oligonucleotides or polycations, which then complexed with pcDNA. Two different synthetic approaches were tested to couple Tf to the surface of chitosan nanoparticles, achieving a conjugation in both cases about 33-43\% (transferrin to chitosan moL\%) [59]. In this study HEK293 cells were transfected using luciferase reporter gene. Tf-conjugated nanoparticles invariably showed threefold greater transfection efficiency than unmodified nanoparticles. However, the Tf-decorated nanoparticles did not show significant enhancement of the transfection of HeLa cells [160].

Tf decoration of chitosan-based DNA-loaded nanoparticles has been found to enhance the transport across polarized monolayer Caco-2 cells known to have abundant Tf receptors on their surface [159] and extensively used as a model of normal intestinal epithelium transport [161]. It was demonstrated that Tf conjugation could enhance the transport of nanoparticles through Caco-2 alone and Caco-2-PPL cocultures by 3 - to 5 -fold. One drawback of these systems is that they only proved to be ineffective in the presence of added serum medium. An interesting contribution of this study was to address the behavior of a coculture of polarized Caco-2 cells infiltrated with lymphocytes that induces the differentiation of M-type phenotype, a model much closer to the real intestinal epithelium. The results led to suggest that uptake in the lymphoid follicles of the duodenum could play a more significant role compared to Peyer's patches [157].

A second related strategy has been to decorate the surface of DNA-loaded chitosan-based nanoparticles with KNOB protein so as to enhance the uptake and overcome one of the major rate-limiting steps for transfection mediated by 
chitosan nanoparticles via a specific receptor-mediated endocytosis mechanism [59]. KNOB conjugation to the nanoparticles significantly improved the transfection efficiency (increased 130 times) when transfecting HeLa cells but still not to a level that could rival Lipofectamine transfection.

\subsection{Hybrid Nanoparticles Comprising Other Polysaccharides.} Yet another approach to enhance the targeting capacity of chitosan-based nanocapsules has been to develop hybrid cogelled systems including other polysaccharides with known affinity toward specific receptors. Among these, nanoparticles comprising hyaluronan, alginate, and glucomannan have deserved attention, particularly for the delivery of insulin, vaccines, and DNA via transmucosa. The reader is referred to recent comprehensive reviews on the subject $[125,127,162]$.

\section{Conclusion}

Pondering advantages and drawbacks, chitosan-based materials represent a very versatile and appealing technological platform to address the design of drug delivery systems that combine unique features such as mucoadhesiveness and enhanced drug absorption for the localized and systemic delivery of drugs through the respiratory system. Furthermore, in a more global perspective that values the potential of the bench-to-bedside translation, relatively low price, commercial availability in a broad spectrum of molecular weights and degrees of deacetylation and chemical versatility are outstanding properties that make of chitosan an excellent candidate in an industrial setting. On the other hand, the lack of reproducibility between batches usually displayed by natural polymers might lead to a less robust production process and remains a challenge to be addressed and overcome. Finally, to date chitosan is approved only as food supplement classified as a "generally recognized as safe" (GRAS) material [4]. In the context of pharmaceutical and biomedical products, a diversity of systems (e.g., micro- and nanoparticles, films, scaffolds, etc.) is under investigation. Remarkably, none of them has been approved by regulatory agencies yet. The diversity of molecular aspects that might affect the biodegradability, biodistribution, and biocompatibility needs to be carefully investigated as straight extrapolations among derivatives seem very complex, if not impossible. Hence, the regulatory phase will also need to be comprehensively addressed if an effective technology transfer and novel endeavors want to be ensured for chitosan and its derivatives.

\section{References}

[1] D. A. Groneberg, C. Witt, U. Wagner, K. F. Chung, and A. Fischer, "Fundamentals of pulmonary drug delivery," Respiratory Medicine, vol. 97, no. 4, pp. 382-387, 2003.

[2] N. R. Labiris and M. B. Dolovich, "Pulmonary drug delivery. Part II: the role of inhalant delivery devices and drug formulations in therapeutic effectiveness of aerosolized medications," British Journal of Clinical Pharmacology, vol. 56, no. 6, pp. 600-612, 2003.

[3] N. R. Labiris and M. B. Dolovich, "Pulmonary drug delivery. Part I: physiological factors affecting therapeutic effectiveness of aerosolized medications," British Journal of Clinical Pharmacology, vol. 56, no. 6, pp. 588-599, 2003.

[4] T. Kean and M. Thanou, "Biodegradation, biodistribution and toxicity of chitosan," Advanced Drug Delivery Reviews, vol. 62 , no. 1, pp. 3-11, 2010.

[5] E. I. Rabea, M. E. T. Badawy, C. V. Stevens, G. Smagghe, and W. Steurbaut, "Chitosan as antimicrobial agent: applications and mode of action," Biomacromolecules, vol. 4, no. 6, pp. 1457-1465, 2003.

[6] W. Xie, P. Xu, and Q. Liu, "Antioxidant activity of watersoluble chitosan derivatives," Bioorganic and Medicinal Chemistry Letters, vol. 11, no. 13, pp. 1699-1701, 2001.

[7] J. C. Fernandes, P. Eaton, H. Nascimento et al., "Antioxidant activity of chitooligosaccharides upon two biological systems: erythrocytes and bacteriophages," Carbohydrate Polymers, vol. 79, no. 4, pp. 1101-1106, 2010.

[8] H. Y. Li and J. Birchall, "Chitosan-modified dry powder formulations for pulmonary gene delivery," Pharmaceutical Research, vol. 23, no. 5, pp. 941-950, 2006.

[9] S. R. Naikwade, A. N. Bajaj, P. Gurav, M. M. Gatne, and P. S. Soni, "Development of budesonide microparticles using spray-drying technology for pulmonary administration: design, characterization, in vitro evaluation, and in vivo efficacy study," AAPS PharmSciTech, vol. 10, no. 3, pp. 993-1012, 2009.

[10] E. H. Lauten, J. VerBerkmoes, J. Choi et al., "Nanoglycan complex formulation extends VEGF retention time in the lung," Biomacromolecules, vol. 11, no. 7, pp. 1863-1872, 2010.

[11] E. J. B. Nielsen, J. M. Nielsen, D. Becker et al., "Pulmonary gene silencing in transgenic EGFP mice using aerosolised chitosan/siRNA nanoparticles," Pharmaceutical Research, vol. 27, no. 12, pp. 2520-2527, 2010.

[12] M. N. V. Kumar, R. A. A. Muzzarelli, C. Muzzarelli, H. Sashiwa, and A. J. Domb, "Chitosan chemistry and pharmaceutical perspectives," Chemical Reviews, vol. 104, no. 12, pp. 60176084, 2004.

[13] I. A. Sogias, A. C. Williams, and V. V. Khutoryanskiy, "Why is chitosan mucoadhesive?" Biomacromolecules, vol. 9, no. 7, pp. 1837-1842, 2008.

[14] V. M. Leitner, G. F. Walker, and A. Bernkop-Schnurch, "Thiolated polymers: evidence for the formation of disulphide bonds with mucus glycoproteins," European Journal of Pharmaceutics and Biopharmaceutics, vol. 56, no. 2, pp. 207-214, 2003.

[15] A. Makhlof, M. Werle, Y. Tozuka, and H. Takeuchi, "Nanoparticles of glycol chitosan and its thiolated derivative significantly improved the pulmonary delivery of calcitonin," International Journal of Pharmaceutics, vol. 397, no. 1-2, pp. 92-95, 2010.

[16] M. Thanou, J. C. Verhoef, and H. E. Junginger, "Chitosan and its derivatives as intestinal absorption enhancers," Advanced Drug Delivery Reviews, vol. 50, supplement 1, pp. S91-S101, 2001.

[17] H. Yamamoto, Y. Kuno, S. Sugimoto, H. Takeuchi, and Y. Kawashima, "Surface-modified PLGA nanosphere with chitosan improved pulmonary delivery of calcitonin by mucoadhesion and opening of the intercellular tight junctions," Journal of Controlled Release, vol. 102, no. 2, pp. 373-381, 2005.

[18] S. C. W. Richardson, H. V. J. Kolbe, and R. Duncan, "Potential of low molecular mass chitosan as a DNA delivery system: biocompatibility, body distribution and ability to complex and protect DNA," International Journal of Pharmaceutics, vol. 178 , no. 2, pp. 231-243, 1999. 
[19] A. Grenha, C. I. Grainger, L. A. Dailey et al., "Chitosan nanoparticles are compatible with respiratory epithelial cells in vitro," European Journal of Pharmaceutical Sciences, vol. 31, no. 2, pp. 73-84, 2007.

[20] Y. Q. Ye, F. Y. Chen, Q. A. Wu et al., "Enhanced cytotoxicity of core modified chitosan based polymeric micelles for doxorubicin delivery," Journal of Pharmaceutical Sciences, vol. 98, no. 2, pp. 704-712, 2009.

[21] C. Witschi and R. J. Mrsny, "In vitro evaluation of microparticles and polymer gels for use as nasal platforms for protein delivery," Pharmaceutical Research, vol. 16, no. 3, pp. 382390, 1999.

[22] B. I. Florea, M. Thanou, H. E. Junginger, and G. Borchard, "Enhancement of bronchial octreotide absorption by chitosan and $\mathrm{N}$-trimethyl chitosan shows linear in vitro/in vivo correlation," Journal of Controlled Release, vol. 110, no. 2, pp. 353-361, 2006.

[23] Y. C. Huang, A. Vieira, K. L. Huang, M. K. Yeh, and C. H. Chiang, "Pulmonary inflammation caused by chitosan microparticles," Journal of Biomedical Materials Research A, vol. 75, no. 2, pp. 283-287, 2005.

[24] M. Choi, M. Cho, B. S. Han et al., "Chitosan nanoparticles show rapid extrapulmonary tissue distribution and excretion with mild pulmonary inflammation to micen," Toxicology Letters, vol. 199, no. 2, pp. 144-152, 2010.

[25] D. A. Zaharoff, C. J. Rogers, K. W. Hance, J. Schlom, and J. W. Greiner, "Chitosan solution enhances both humoral and cellmediated immune responses to subcutaneous vaccination," Vaccine, vol. 25, no. 11, pp. 2085-2094, 2007.

[26] J. Kreuter, "Nanoparticles—a historical perspective," International Journal of Pharmaceutics, vol. 331, no. 1, pp. 1-10, 2007.

[27] J. C. Sung, B. L. Pulliam, and D. A. Edwards, "Nanoparticles for drug delivery to the lungs," Trends in Biotechnology, vol. 25, no. 12, pp. 563-570, 2007.

[28] R. Pandey, A. Sharma, A. Zahoor, S. Sharma, G. K. Khuller, and B. Prasad, "Poly (dl-lactide-co-glycolide) nanoparticlebased inhalable sustained drug delivery system for experimental tuberculosis," Journal of Antimicrobial Chemotherapy, vol. 52, no. 6, pp. 981-986, 2003.

[29] M. Bivas-Benita, M. Y. Lin, S. M. Bal et al., "Pulmonary delivery of DNA encoding Mycobacterium tuberculosis latency antigen Rv1733c associated to PLGA-PEI nanoparticles enhances $\mathrm{T}$ cell responses in a DNA prime/protein boost vaccination regimen in mice," Vaccine, vol. 27 , no. 30 , pp. 4010-4017, 2009.

[30] J. C. Sung, D. J. Padilla, L. Garcia-Contreras et al., "Formulation and pharmacokinetics of self-assembled rifampicin nanoparticle systems for pulmonary delivery," Pharmaceutical Research, vol. 26, no. 8, pp. 1847-1855, 2009.

[31] B. Bharatwaj, L. Wu, J. A. Whittum-Hudson, and S. R. P. da Rocha, "The potential for the noninvasive delivery of polymeric nanocarriers using propellant-based inhalers in the treatment of Chlamydial respiratory infections," Biomaterials, vol. 31, no. 28, pp. 7376-7385, 2010.

[32] A. Grenha, C. Remunan-Lopez, E. L. Carvalho, and B. Seijo, "Microspheres containing lipid/chitosan nanoparticles complexes for pulmonary delivery of therapeutic proteins," European Journal of Pharmaceutics and Biopharmaceutics, vol. 69, no. 1, pp. 83-93, 2008.

[33] A. B. Sieval, M. Thanou, A. F. Kotzé, J. C. Verhoef, J. Brussee, and H. E. Junginger, "Preparation and NMR characterization of highly substituted N-trimethyl chitosan chloride," Carbohydrate Polymers, vol. 36, no. 2-3, pp. 157-165, 1998.
[34] A. F. Kotzé, M. M. Thanou, H. L. Lueßen, A. B. G. de Boer, J. C. Verhoef, and H. E. Junginger, "Effect of the degree of quaternization of N-trimethyl chitosan chloride on the permeability of intestinal epithelial cells (Caco-2)," European Journal of Pharmaceutics and Biopharmaceutics, vol. 47, no. 3, pp. 269-274, 1999.

[35] M. Thanou, J. C. Verhoef, J. H. M. Verheijden, and H. E. Junginger, "Intestinal absorption of octreotide using trimethyl chitosan chloride: studies in pigs," Pharmaceutical Research, vol. 18, no. 6, pp. 823-828, 2001.

[36] J. H. Hamman, M. Stander, and A. F. Kotzé, "Effect of the degree of quaternisation of N-trimethyl chitosan chloride on absorption enhancement: in vivo evaluation in rat nasal epithelia," International Journal of Pharmaceutics, vol. 232, no. 1-2, pp. 235-242, 2002.

[37] J. H. Hamman, C. M. Schultz, and A. F. Kotze, "N-trimethyl chitosan chloride: optimum degree of quaternization for drug absorption enhancement across epithelial cells," Drug Development and Industrial Pharmacy, vol. 29, no. 2, pp. 161$172,2003$.

[38] B. Sayin, S. Somavarapu, X. W. Li, D. Sesardic, S. Senel, and O. H. Alpar, "TMC-MCC (N-trimethyl chitosan-mono-Ncarboxymethyl chitosan) nanocomplexes for mucosal delivery of vaccines," European Journal of Pharmaceutical Sciences, vol. 38, no. 4, pp. 362-369, 2009.

[39] F. Chen, Z.-R. Zhang, and Y. Huang, "Evaluation and modification of N-trimethyl chitosan chloride nanoparticles as protein carriers," International Journal of Pharmaceutics, vol. 336, no. 1, pp. 166-173, 2007.

[40] M. M. Issa, M. Köping-Höggård, and P. Artursson, "Chitosan and the mucosal delivery of biotechnology drugs," Drug Discovery Today, vol. 2, no. 1, pp. 1-6, 2005.

[41] B. Sayin, S. Somavarapu, X. G. Li, O. Alpar, and S. Senel, "A new vaccine delivery system with chitosan derivatives for intranasal immunization: in vitro/in vivo evaluations," in Advances in Chiton Science, S. Senel, K. M. Varum, M. M. Sumnu, and A. A. Hincal, Eds., vol. 10, pp. 219-224, Alp Ofset, Ankara , Turky, 2007.

[42] M. Amidi, S. G. Romeijn, G. Borchard, H. E. Junginger, W. E. Hennink, and W. Jiskoot, "Preparation and characterization of protein-loaded N-trimethyl chitosan nanoparticles as nasal delivery system," Journal of Controlled Release, vol. 111, no. 1-2, pp. 107-116, 2006.

[43] B. Slütter, S. M. Bal, I. Que et al., "Antigen-adjuvant nanoconjugates for nasal vaccination: an improvement over the use of nanoparticles?" Molecular Pharmaceutics, vol. 7, no. 6, pp. 2207-2215, 2010.

[44] B. Slütter and W. Jiskoot, "Dual role of CpG as immune modulator and physical crosslinker in ovalbumin loaded N-trimethyl chitosan (TMC) nanoparticles for nasal vaccination," Journal of Controlled Release, vol. 148, no. 1, pp. 117-121, 2010.

[45] B. Slutter, P. C. Soema, Z. Ding, R. Verheul, W. Hennink, and W. Jiskoot, "Conjugation of ovalbumin to trimethyl chitosan improves immunogenicity of the antigen," Journal of Controlled Release, vol. 143, no. 2, pp. 207-214, 2010.

[46] A. Anitha, S. Maya, N. Deepa et al., "Efficient water soluble O-carboxymethyl chitosan nanocarrier for the delivery of curcumin to cancer cells," Carbohydrate Polymers, vol. 83, no. 2, pp. 452-461, 2011.

[47] M. J. Laudenslager, J. D. Schiffman, and C. L. Schauer, "Carboxymethyl chitosan as a matrix material for platinum, gold, and silver nanoparticles," Biomacromolecules, vol. 9, no. 10, pp. 2682-2685, 2008. 
[48] N. T. An, D. T. Thien, N. T. Dong, and P. L. Dung, "Watersoluble N-carboxymethylchitosan derivatives: preparation, characteristics and its application," Carbohydrate Polymers, vol. 75, no. 3, pp. 489-497, 2009.

[49] X. Shi, Y. Du, J. Yang, B. Zhang, and L. Sun, "Effect of degree of substitution and molecular weight of carboxymethyl chitosan nanoparticles on doxorubicin delivery," Journal of Applied Polymer Science, vol. 100, no. 6, pp. 4689-4696, 2006.

[50] J. Liang, F. Li, Y. Fang et al., "Synthesis, characterization and cytotoxicity studies of chitosan-coated tea polyphenols nanoparticles," Colloids and Surfaces B, vol. 82, no. 2, pp. 297-301, 2011.

[51] Y. Li, S. Zhang, X. Meng, X. Chen, and G. Ren, “The preparation and characterization of a novel amphiphilic oleoylcarboxymethyl chitosan self-assembled nanoparticles," Carbohydrate Polymers, vol. 83, no. 1, pp. 130-136, 2011.

[52] C. Yan, D. Chen, J. Gu, H. Hu, X. Zhao, and M. Qiao, "Preparation of $\mathrm{N}$-succinyl-chitosan and their physical-chemical properties as a novel excipient," Yakugaku Zasshi, vol. 126, no. 9, pp. 789-793, 2006.

[53] Z. Hou, J. Han, C. Zhan, C. Zhou, Q. Hu, and Q. Zhang, "Synthesis and evaluation of N-succinyl-chitosan nanoparticles toward local hydroxycamptothecin delivery," Carbohydrate Polymers, vol. 81, no. 4, pp. 765-768, 2010.

[54] C. Yan, J. Gu, Y. Guo, and D. Chen, "In vivo biodistribution for tumor targeting of 5-fluorouracil (5-FU) loaded Nsuccinyl-chitosan (Suc-Chi) nanoparticles," Yakugaku Zasshi, vol. 130, no. 6, pp. 801-804, 2010.

[55] H. Luo, J. Li, and X. Chen, "Antitumor effect of N-succinylchitosan nanoparticles on K562 cells," Biomedicine and Pharmacotherapy, vol. 64, no. 8, pp. 521-526, 2010.

[56] A. Dal Pozzo, L. Vanini, M. Fagnoni, M. Guerrini, A. De Benedittis, and R. A. A. Muzzarelli, "Preparation and characterization of poly(ethylene glycol)-crosslinked reacetylated chitosans," Carbohydrate Polymers, vol. 42, no. 2, pp. 201206, 2000.

[57] X. Zhang, H. Zhang, Z. Wu, Z. Wang, H. Niu, and C. Li, "Nasal absorption enhancement of insulin using PEG-grafted chitosan nanoparticles," European Journal of Pharmaceutics and Biopharmaceutics, vol. 68, no. 3, pp. 526-534, 2008.

[58] O. Germershaus, S. Mao, J. Sitterberg, U. Bakowsky, and T. Kissel, "Gene delivery using chitosan, trimethyl chitosan or polyethylenglycol-graft-trimethyl chitosan block copolymers: establishment of structure-activity relationships in vitro," Journal of Controlled Release, vol. 125, no. 2, pp. 145154, 2008.

[59] H. Q. Mao, K. Roy, V. L. Troung-Le et al., "Chitosan-DNA nanoparticles as gene carriers: synthesis, characterization and transfection efficiency," Journal of Controlled Release, vol. 70, no. 3, pp. 399-421, 2001.

[60] W. J. Lin, T. D. Chen, C. W. Liu, J. L. Chen, and F. H. Chang, "Synthesis of lactobionic acid-grafted-pegylated-chitosan with enhanced HepG2 cells transfection," Carbohydrate Polymers, vol. 83, no. 2, pp. 898-904, 2011.

[61] A. Bernkop-Schnürch, M. Hornof, and D. Guggi, "Thiolated chitosans," European Journal of Pharmaceutics and Biopharmaceutics, vol. 57, no. 1, pp. 9-17, 2004.

[62] X. Wang, C. Zheng, and Z. M. Wu, "Chitosan-NAC nanoparticles as a vehicle for nasal absorption enhancement of insulin," Journal of Biomedical Materials Research Part B, vol. 88, no. 1, pp. 150-161, 2009.

[63] V. P. Torchilin, "Micellar nanocarriers: pharmaceutical perspectives," Pharmaceutical Research, vol. 24, no. 1, pp. 1-16, 2007.
[64] G. Gaucher, M. H. Dufresne, V. P. Sant, N. Kang, D. Maysinger, and J. C. Leroux, "Block copolymer micelles: preparation, characterization and application in drug delivery," Journal of Controlled Release, vol. 109, no. 1-3, pp. 169-188, 2005.

[65] M. C. Jones and J. C. Leroux, "Polymeric micelles-a new generation of colloidal drug carriers," European Journal of Pharmaceutics and Biopharmaceutics, vol. 48, no. 2, pp. 101$111,1999$.

[66] G. S. Kwon and T. Okano, "Polymeric micelles as new drug carriers," Advanced Drug Delivery Reviews, vol. 21, no. 2, pp. 107-116, 1996.

[67] Physiologically Active Polypeptide- or Protein-Encapsulating Polymer Micelles, and Method for Production of the Same.

[68] A. V. Kabanov, E. V. Batrakova, and V. Y. Alakhov, "Pluronic block copolymers as novel polymer therapeutics for drug and gene delivery," Journal of Controlled Release, vol. 82, no. 2-3, pp. 189-212, 2002.

[69] A. Benahmed, M. Ranger, and J. C. Leroux, "Novel polymeric micelles based on the amphiphilic diblock copolymer poly(N-vinyl-2-pyrrolidone)-block-poly(D,L-lactide)," Pharmaceutical Research, vol. 18, no. 3, pp. 323-328, 2001.

[70] H. M. Aliabadi, A. Mahmud, A. D. Sharifabadi, and A. Lavasanifar, "Micelles of methoxy poly(ethylene oxide)-b-poly (epsilon-caprolactone) as vehicles for the solubilization and controlled delivery of cyclosporine A," Journal of Controlled Release, vol. 104, no. 2, pp. 301-311, 2005.

[71] A. A. Exner, T. M. Krupka, K. Scherrer, and J. M. Teets, "Enhancement of carboplatin toxicity by Pluronic block copolymers," Journal of Controlled Release, vol. 106, no. 1-2, pp. 188-197, 2005.

[72] J. Wang, D. Mongayt, and V. P. Torchilin, "Polymeric micelles for delivery of poorly soluble drugs: preparation and anticancer activity in vitro of paclitaxel incorporated into mixed micelles based on poly(ethylene glycol)-lipid conjugate and positively charged lipids," Journal of Drug Targeting, vol. 13, no. 1, pp. 73-80, 2005.

[73] M. Watanabe, K. Kawano, M. Yokoyama, P. Opanasopit, T. Okano, and Y. Maitani, "Preparation of camptothecin-loaded polymeric micelles and evaluation of their incorporation and circulation stability," International Journal of Pharmaceutics, vol. 308, no. 1-2, pp. 183-189, 2006.

[74] J. Liaw, S. F. Chang, and F. C. Hsiao, "In vivo gene delivery into ocular tissues by eye drops of poly(ethylene oxide)poly(propylene oxide)-poly(ethylene oxide) (PEO-PPOPEO) polymeric micelles," Gene Therapy, vol. 8, no. 13, pp. 999-1004, 2001.

[75] V. P. Torchilin, "PEG-based micelles as carriers of contrast agents for different imaging modalities," Advanced Drug Delivery Reviews, vol. 54, no. 2, pp. 235-252, 2002.

[76] P. Opanasopit, M. Yokoyama, M. Watanabe, K. Kawano, Y. Maitani, and T. Okano, "Block copolymer design for camptothecin incorporation into polymeric micelles for passive tumor targeting," Pharmaceutical Research, vol. 21, no. 11, pp. 2001-2008, 2004.

[77] U. Kedar, P. Phutane, S. Shidhaye, and V. Kadam, "Advances in polymeric micelles for drug delivery and tumor targeting," Nanomedicine, vol. 6, no. 6, pp. 714-729, 2010.

[78] N. Rapoport, "Physical stimuli-responsive polymeric micelles for anti-cancer drug delivery," Progress in Polymer Science, vol. 32, no. 8-9, pp. 962-990, 2007.

[79] Q. Yuan, R. Venkatasubramanian, S. Hein, and R. D. K. Misra, "A stimulus-responsive magnetic nanoparticle drug carrier: magnetite encapsulated by chitosan-grafted-copolymer," Acta Biomaterialia, vol. 4, no. 4, pp. 1024-1037, 2008. 
[80] Y. Bae, W. D. Jang, N. Nishiyama, S. Fukushima, and K. Kataoka, "Multifunctional polymeric micelles with folatemediated cancer cell targeting and $\mathrm{pH}$-triggered drug releasing properties for active intracellular drug delivery," Molecular BioSystems, vol. 1, no. 3, pp. 242-250, 2005.

[81] M. Smola, T. Vandamme, and A. Sokolowski, "Nanocarriers as pulmonary drug delivery systems to treat and to diagnose respiratory and non respiratory diseases," International Journal of Nanomedicine, vol. 3, no. 1, pp. 1-19, 2008.

[82] Y. T. Yang, C. T. Chen, J. C. Yang, and T. Tsai, "Spray-dried microparticles containing polymeric micelles encapsulating hematoporphyrin," AAPS Journal, vol. 12, no. 2, pp. 138-146, 2010.

[83] N. N. Gaber, Y. Darwis, K. K. Peh, and Y. T. F. Tan, "Characterization of polymeric micelles for pulmonary delivery of beclomethasone dipropionate," Journal of Nanoscience and Nanotechnology, vol. 6, no. 9-10, pp. 3095-3101, 2006.

[84] M. Silva, A. S. Lara, C. Q. F. Leite, and E. I. Ferreira, "Potential tuberculostatic agents: micelle-forming copolymer poly(ethylene glycol)-poly(aspartic acid) prodrug with isoniazid," Archiv Der Pharmazie, vol. 334, no. 6, pp. 189-193, 2001.

[85] M. Silva, N. L. Ricelli, O. El Seoud et al., "Potential tuberculostatic agent: micelle-forming pyrazinamide prodrug," Archiv Der Pharmazie, vol. 339, no. 6, pp. 283-290, 2006.

[86] J. M. A. Abdulla, Y. T. F. Tan, and Y. Darwis, "Rehydrated lyophilized rifampicin-loaded mPEG-DSPE formulations for nebulization," AAPS PharmSciTech, vol. 11, no. 2, pp. 663$671,2010$.

[87] Y. C. Chao, S. F. Chang, S. C. Lu, T. C. Hwang, W. H. Hsieh, and J. Liaw, "Ethanol enhanced in vivo gene delivery with non-ionic polymeric micelles inhalation," Journal of Controlled Release, vol. 118, no. 1, pp. 105-117, 2007.

[88] F. Q. Hu, M. D. Zhao, H. Yuan, J. You, Y. Z. Du, and S. Zeng, "A novel chitosan oligosaccharide-stearic acid micelles for gene delivery: properties and in vitro transfection studies," International Journal of Pharmaceutics, vol. 315, no. 1-2, pp. 158-166, 2006.

[89] F. Q. Hu, G. F. Ren, H. Yuan, Y. Z. Du, and S. Zeng, "Shell cross-linked stearic acid grafted chitosan oligosaccharide self-aggregated micelles for controlled release of paclitaxel," Colloids and Surfaces B, vol. 50, no. 2, pp. 97-103, 2006.

[90] F. Q. Hu, X. L. Wu, Y. Z. Du, J. You, and H. Yuan, "Cellular uptake and cytotoxicity of shell crosslinked stearic acidgrafted chitosan oligosaccharide micelles encapsulating doxorubicin," European Journal of Pharmaceutics and Biopharmaceutics, vol. 69, no. 1, pp. 117-125, 2008.

[91] F. Q. Hu, L. N. Liu, Y. Z. Du, and H. Yuan, "Synthesis and antitumor activity of doxorubicin conjugated stearic acidg-chitosan oligosaccharide polymeric micelles," Biomaterials, vol. 30, no. 36, pp. 6955-6963, 2009.

[92] F. Q. Hu, Y. H. Li, H. Yuan, and S. Zeng, "Novel selfaggregates of chitosan oligosaccharide grafted stearic acid: preparation, characterization and protein association," Pharmazie, vol. 61, no. 3, pp. 194-198, 2006.

[93] K. Gilani, E. Moazeni, T. Ramezanli, M. Amini, M. R. Fazeli, and H. Jamalifar, "Development of respirable nanomicelle carriers for delivery of amphotericin B by jet nebulization," Journal of Pharmaceutical Sciences, vol. 100, no. 1, pp. 252259, 2011.

[94] B. J. Rijnders, J. J. Cornelissen, L. Slobbe et al., "Aerosolized liposomal amphotericin B for the prevention of invasive pulmonary aspergillosis during prolonged neutropenia: a randomized, placebo-controlled trial," Clinical Infectious Diseases, vol. 46, no. 9, pp. 1401-1408, 2008.

[95] J. Barwicz, S. Christian, and I. Gruda, "Effects of the aggregation state of amphotericin B on its toxicity to mice," Antimicrobial Agents and Chemotherapy, vol. 36, no. 10, pp. 23102315, 1992.

[96] D. Z. Liu, J. H. Hsieh, X. C. Fan, J. D. Yang, and T. W. Chung, "Synthesis, characterization and drug delivery behaviors of new PCP polymeric micelles," Carbohydrate Polymers, vol. 68, no. 3, pp. 544-554, 2007.

[97] C. Chen, G. Cai, H. Zhang, H. Jiang, and L. Wang, "Chitosanpoly( $\varepsilon$-caprolactone)-poly(ethylene glycol) graft copolymers: synthesis, self-assembly, and drug release behavior," Journal of Biomedical Materials Research A, vol. 96, no. 1, pp. 116-124, 2011.

[98] Y. Wu, M. Li, and H. Gao, "Polymeric micelle composed of PLA and chitosan as a drug carrier," Journal of Polymer Research, vol. 16, no. 1, pp. 11-18, 2009.

[99] H. Yoshioka, K. Nonaka, K. Fukuda, and S. Kazama, "Chitosan-derived polymer-surfactants and their micellar properties," Bioscience, Biotechnology, and Biochemistry, vol. 59, no. 10, pp. 1901-1904, 1995.

[100] C. Zhang, Y. Ding, Q. Ping, and L. Yu, "Novel chitosanderived nanomaterials and their micelle-forming properties," Journal of Agricultural and Food Chemistry, vol. 54, no. 22, pp. 8409-8416, 2006.

[101] I. Aranaz, R. Harris, and A. Heras, "Chitosan amphiphilic derivatives. Chemistry and applications," Current Organic Chemistry, vol. 14, no. 3, pp. 308-330, 2010.

[102] C. Zhang, Q. Ping, H. Zhang, and J. Shen, "Preparation of $\mathrm{N}$-alkyl-O-sulfate chitosan derivatives and micellar solubilization of taxol," Carbohydrate Polymers, vol. 54, no. 2, pp. 137-141, 2003.

[103] C. Zhang, G. Qu, Y. Sun et al., "Pharmacokinetics, biodistribution, efficacy and safety of N-octyl-O-sulfate chitosan micelles loaded with paclitaxel," Biomaterials, vol. 29, no. 9, pp. 1233-1241, 2008.

[104] C. Zhang, Y. Ding, L. Yu, and Q. Ping, "Polymeric micelle systems of hydroxycamptothecin based on amphiphilic Nalkyl-N-trimethyl chitosan derivatives," Colloids and Surfaces B, vol. 55, no. 2, pp. 192-199, 2007.

[105] X. Xiangyang, L. Ling, Z. Jianping et al., "Preparation and characterization of $\mathrm{N}$-succinyl-N'-octyl chitosan micelles as doxorubicin carriers for effective anti-tumor activity," Colloids and Surfaces B, vol. 55, no. 2, pp. 222-228, 2007.

[106] G. Qu, Z. Yao, C. Zhang, X. Wu, and Q. Ping, "PEG conjugated N-octyl-O-sulfate chitosan micelles for delivery of paclitaxel: in vitro characterization and in vivo evaluation," European Journal of Pharmaceutical Sciences, vol. 37, no. 2, pp. 98-105, 2009.

[107] A. Miwa, A. Ishibe, M. Nakano et al., "Development of novel chitosan derivatives as micellar carriers of taxol," Pharmaceutical Research, vol. 15, no. 12, pp. 1844-1850, 1998.

[108] J. Liu, H. Li, D. Chen et al., "In vivo evaluation of novel chitosan graft polymeric micelles for delivery of paclitaxel," Drug Delivery, vol. 18, no. 3, pp. 181-189, 2011.

[109] Y. Z. Du, L. Wang, H. Yuan, X. H. Wei, and F. Q. Hu, "Preparation and characteristics of linoleic acid-grafted chitosan oligosaccharide micelles as a carrier for doxorubicin," Colloids and Surfaces B, vol. 69, no. 2, pp. 257-263, 2009.

[110] Y. Z. Du, L. Wang, H. Yuan, and F. Q. Hu, "Linoleic acidgrafted chitosan oligosaccharide micelles for intracellular drug delivery and reverse drug resistance of tumor cells," 
International Journal of Biological Macromolecules, vol. 48, no. 1, pp. 215-222, 2011.

[111] Y. L. Jeong, D. H. Seo, D. G. Kim et al., "Methotrexateincorporated polymeric micelles composed of methoxy poly (ethylene glycol)-grafted chitosan," Macromolecular Research, vol. 17, no. 7, pp. 538-543, 2009.

[112] D. H. Seo, Y. I. Jeong, D. G. Kim, M. J. Jang, M. K. Jang, and J. W. Nah, "Methotrexate-incorporated polymeric nanoparticles of methoxy poly(ethylene glycol)-grafted chitosan," Colloids and Surfaces B, vol. 69, no. 2, pp. 157-163, 2009.

[113] C. M. Lehr, J. A. Bouwstra, E. H. Schacht, and H. E. Junginger, "In vitro evaluation of mucoadhesive properties of chitosan and some other natural polymers," International Journal of Pharmaceutics, vol. 78, no. 1, pp. 43-48, 1992.

[114] C. Shruti, M. Saiqa, K. Jasjeet, I. Zeemat, T. Sushma, and F. J. Ahmad, "Advances and potential applications of chitosan derivatives as mucoadhesive biomaterials in modern drug delivery," Journal of Pharmacy and Pharmacology, vol. 58, no. 8, pp. 1021-1032, 2006.

[115] C. Chatelet, O. Damour, and A. Domard, "Influence of the degree of acetylation on some biological properties of chitosan films," Biomaterials, vol. 22, no. 3, pp. 261-268, 2001.

[116] P. J. Vandevord, H. W. T. Matthew, S. P. Desilva, L. Mayton, B. $\mathrm{Wu}$, and P. H. Wooley, "Evaluation of the biocompatibility of a chitosan scaffold in mice," Journal of Biomedical Materials Research, vol. 59, no. 3, pp. 585-590, 2002.

[117] P. Artursson, T. Lindmark, S. S. Davis, and L. Illum, "Effect of chitosan on the permeability of monolayers of intestinal epithelial cells (Caco-2)," Pharmaceutical Research, vol. 11, no. 9, pp. 1358-1361, 1994.

[118] N. G. M. Schipper, S. Olsson, J. A. Hoogstraate, A. G. DeBoer, K. M. Vårum, and P. Artursson, "Chitosans as absorption enhancers for poorly absorbable drugs 2: mechanism of absorption enhancement," Pharmaceutical Research, vol. 14, no. 7, pp. 923-929, 1997.

[119] V. Dodane, M. A. Khan, and J. R. Merwin, "Effect of chitosan on epithelial permeability and structure," International Journal of Pharmaceutics, vol. 182, no. 1, pp. 21-32, 1999.

[120] J. Smith, E. Wood, and M. Dornish, "Effect of chitosan on epithelial cell tight junctions," Pharmaceutical Research, vol. 21, no. 1, pp. 43-49, 2004.

[121] R. Fernandez-Urrusuno, P. Calvo, C. Remuñán-López, J. L. Vila-Jato, and M. J. Alonso, "Enhancement of nasal absorption of insulin using chitosan nanoparticles," Pharmaceutical Research, vol. 16, no. 10, pp. 1576-1581, 1999.

[122] K. A. Janes, P. Calvo, and M. J. Alonso, "Polysaccharide colloidal particles as delivery systems for macromolecules," Advanced Drug Delivery Reviews, vol. 47, no. 1, pp. 83-97, 2001.

[123] A. Vila, A. Sánchez, K. Janes et al., "Low molecular weight chitosan nanoparticles as new carriers for nasal vaccine delivery in mice," European Journal of Pharmaceutics and Biopharmaceutics, vol. 57, no. 1, pp. 123-131, 2004.

[124] C. Prego, D. Torres, and M. J. Alonso, "Chitosan nanocapsules: a new carrier for nasal peptide delivery," Journal of Drug Delivery Science and Technology, vol. 16, no. 5, pp. 331-337, 2006.

[125] N. Csaba, M. Garcia-Fuentes, and M. J. Alonso, "Nanoparticles for nasal vaccination," Advanced Drug Delivery Reviews, vol. 61, no. 2, pp. 140-157, 2009.

[126] T. Kean, S. Roth, and M. Thanou, "Trimethylated chitosans as non-viral gene delivery vectors: cytotoxicity and transfection efficiency," Journal of Controlled Release, vol. 103, no. 3, pp. 643-653, 2005.
[127] M. J. Alonso, C. Prego, and M. García-Fuentes, "Polysaccharide-based nanoparticles as carriers for drug and vaccine delivery," in Nanoparticles for Pharmaceutical Application, J. Domb, Y. Tabata, M. N. V. R. Kumar, and S. Farber, Eds., pp. 135-150, American Scientific Publishers, Stevenson Ranch, Calif, USA, 2007.

[128] F. Zheng, X. W. Shi, G. F. Yang et al., "Chitosan nanoparticle as gene therapy vector via gastrointestinal mucosa administration: results of an in vitro and in vivo study," Life Sciences, vol. 80, no. 4, pp. 388-396, 2007.

[129] M. de la Fuente, B. Seijo, and M. J. Alonso, "Novel hyaluronan-based nanocarriers for transmucosal delivery of macromolecules," Macromolecular Bioscience, vol. 8, no. 5, pp. 441-450, 2008.

[130] D. Teijeiro-Osorio, C. Remuñán-López, and M. J. Alonso, "New generation of hybrid poly/oligosaccharide nanoparticles as carriers for the nasal delivery of macromolecules," Biomacromolecules, vol. 10, no. 2, pp. 243-249, 2009.

[131] M. M. Thanou, A. F. Kotzé, T. Scharringhausen et al., "Effect of degree of quaternization of $\mathrm{N}$-trimethyl chitosan chloride for enhanced transport of hydrophilic compounds across intestinal Caco-2 cell monolayers," Journal of Controlled Release, vol. 64, no. 1-3, pp. 15-25, 2000.

[132] Y. K. Park, Y. H. Park, B. A. Shin et al., "Galactosylated chitosan-graft-dextran as hepatocyte-targeting DNA carrier," Journal of Controlled Release, vol. 69, no. 1, pp. 97-108, 2000.

[133] P. Erbacher, S. Zou, T. Bettinger, A.-M. Steffan, and J.S. Remy, "Chitosan-based vector/DNA complexes for gene delivery: biophysical characteristics and transfection ability," Pharmaceutical Research, vol. 15, no. 9, pp. 1332-1339, 1998.

[134] T. H. Kim, H. Jin, H. W. Kim, M. H. Cho, and C. S. Cho, "Mannosylated chitosan nanoparticle-based cytokine gene therapy suppressed cancer growth in BALB/c mice bearing CT-26 carcinoma cells," Molecular Cancer Therapeutics, vol. 5, no. 7, pp. 1723-1732, 2006.

[135] M. M. Issa, M. Köping-Höggård, K. Tømmeraas et al., "Targeted gene delivery with trisaccharide-substituted chitosan oligomers in vitro and after lung administration in vivo," Journal of Controlled Release, vol. 115, no. 1, pp. 103-112, 2006.

[136] N. Duceppe and M. Tabrizian, "Advances in using chitosanbased nanoparticles for in vitro and in vivo drug and gene delivery," Expert Opinion on Drug Delivery, vol. 7, no. 10, pp. 1191-1207, 2010.

[137] A. C. Antony, "Folate receptors," Annual Review of Nutrition, vol. 16, pp. 501-521, 1996.

[138] R. J. Lee and P. S. Low, "Delivery of liposomes into cultured $\mathrm{KB}$ cells via folate receptor-mediated endocytosis," Journal of Biological Chemistry, vol. 269, no. 5, pp. 3198-3204, 1994.

[139] M. J. Turk, G. J. Breur, W. R. Widmer et al., "Folate-targeted imaging of activated macrophages in rats with adjuvantinduced arthritis," Arthritis and Rheumatism, vol. 46, no. 7, pp. 1947-1955, 2002.

[140] S. Mansouri, Y. Cuie, F. Winnik et al., "Characterization of folate-chitosan-DNA nanoparticles for gene therapy," Biomaterials, vol. 27, no. 9, pp. 2060-2065, 2006.

[141] Y. Zheng, Z. Cai, X. Song et al., "Preparation and characterization of folate conjugated $\mathrm{N}$-trimethyl chitosan nanoparticles as protein carrier targeting folate receptor: in vitro studies," Journal of Drug Targeting, vol. 17, no. 4, pp. 294303, 2009.

[142] Y. Zheng, Z. Cai, X. Song et al., "Receptor mediated gene delivery by folate conjugated N-trimethyl chitosan in vitro," 
International Journal of Pharmaceutics, vol. 382, no. 1-2, pp. 262-269, 2009.

[143] S. J. Yang, F. H. Lin, K. C. Tsai et al., "Folic acid-conjugated chitosan nanoparticles enhanced protoporphyrin IX accumulation in colorectal cancer cells," Bioconjugate Chemistry, vol. 21, no. 4, pp. 679-689, 2010.

[144] J. Zhou, G. Romero, E. Rojas, L. Ma, S. Moya, and C. Gao, "Layer by layer chitosan/alginate coatings on poly(lactide-coglycolide) nanoparticles for antifouling protection and folic acid binding to achieve selective cell targeting," Journal of Colloid and Interface Science, vol. 345, no. 2, pp. 241-247, 2010.

[145] D. Bhattacharya, M. Das, D. Mishra et al., "Folate receptor targeted, carboxymethyl chitosan functionalized iron oxide nanoparticles: a novel ultradispersed nanoconjugates for bimodal imaging," Nanoscale, vol. 3, no. 4, pp. 1653-1662, 2011.

[146] P. Li, Y. Wang, F. Zeng, L. Chen, Z. Peng, and L. X. Kong, "Synthesis and characterization of folate conjugated chitosan and cellular uptake of its nanoparticles in HT-29 cells," Carbohydrate Research, vol. 346, no. 6, pp. 801-806, 2011.

[147] S. K. Sahu, S. Maiti, T. K. Maiti, S. K. Ghosh, and P. Pramanik, "Hydrophobically modified carboxymethyl chitosan nanoparticles targeted delivery of paclitaxel," Journal of Drug Targeting, vol. 19, no. 2, pp. 104-113, 2011.

[148] Q. Shi, H. Wang, C. Tran et al., "Hydrodynamic delivery of chitosan-folate-DNA nanoparticles in rats with adjuvantinduced arthritis," Journal of Biomedicine and Biotechnology, vol. 2011, Article ID 148763, 9 pages, 2011.

[149] Y. 1. Tan and C. G. Liu, "Preparation and characterization of self-assemblied nanoparticles based on folic acid modified carboxymethyl chitosan," Journal of Materials Science, vol. 22, no. 5, pp. 1213-1220, 2011.

[150] S. K. Sahu, S. K. Mallick, S. Santra, T. K. Maiti, S. K. Ghosh, and P. Pramanik, "In vitro evaluation of folic acid modified carboxymethyl chitosan nanoparticles loaded with doxorubicin for targeted delivery," Journal of Materials Science, vol. 21, no. 5, pp. 1587-1597, 2010.

[151] C. C. Chiu, Y. T. Lin, S. L. Sun, K. H. Sung, and L. F. Wang, "Anticancer activity of released doxorubicin from a folatemediated polyelectrolyte complex," Journal of Biomaterials Science, Polymer Edition, vol. 22, no. 11, pp. 1487-1507, 2011.

[152] V. B. Morris and C. P. Sharma, "Folate mediated histidine derivative of quaternised chitosan as a gene delivery vector," International Journal of Pharmaceutics, vol. 389, no. 1-2, pp. 176-185, 2010.

[153] L. Fan, F. Li, H. Zhang et al., "Co-delivery of PDTC and doxorubicin by multifunctional micellar nanoparticles to achieve active targeted drug delivery and overcome multidrug resistance," Biomaterials, vol. 31 , no. 21, pp. 5634 $5642,2010$.

[154] Z. Liu, Z. Zhong, G. Peng et al., "Folate receptor mediated intracellular gene delivery using the charge changing solid lipid nanoparticles," Drug Delivery, vol. 16, no. 6, pp. 341347, 2009.

[155] C. Fan, W. Gao, Z. Chen et al., "Tumor selectivity of stealth multi-functionalized superparamagnetic iron oxide nanoparticles," International Journal of Pharmaceutics, vol. 404, no. 1-2, pp. 180-190, 2011.

[156] J. C. Fernandes, H. Wang, C. Jreyssaty et al., "Bone-protective effects of nonviral gene therapy with folate-chitosan DNA nanoparticle containing interleukin-1 receptor antagonist gene in rats with adjuvant-induced arthritis," Molecular Therapy, vol. 16, no. 7, pp. 1243-1251, 2008.
[157] I. Kadiyala, Y. Loo, K. Roy, J. Rice, and K. W. Leong, “Transport of chitosan-DNA nanoparticles in human intestinal Mcell model versus normal intestinal enterocytes," European Journal of Pharmaceutical Sciences, vol. 39, no. 1-3, pp. 103$109,2010$.

[158] A. Dautry-Varsat, "Receptor-mediated endocytosis: the intracellular journey of transferrin and its receptor," Biochimie, vol. 68, no. 3, pp. 375-381, 1986.

[159] Z. B. Zhu, S. K. Makhija, B. Lu et al., "Transport across a polarized monolayer of Caco-2 cells by transferrin receptormediated adenovirus transcytosis," Virology, vol. 325, no. 1, pp. 116-128, 2004.

[160] N. Fang, V. Chan, H. Q. Mao, and K. W. Leong, "Interactions of phospholipid bilayer with chitosan: effect of molecular weight and pH," Biomacromolecules, vol. 2, no. 4, pp. 11611168, 2001.

[161] P. Artursson, "Epithelial transport of drugs in cell culture. I. Amodel for studying the passive diffusion of drugs over intestinal absorptive (Caco-2) cells," Journal of Pharmaceutical Sciences, vol. 79, pp. 476-482, 1990.

[162] F. M. Goycoolea, I. Higuera-Ciapara, and M. J. Alonso, "Chitosan-polysaccharide blended nanoparticles for controlled drug delivery," in Handbook of Natural-based Polymers for Biomedical Applications, R. L. Reis, N. M. Neves, J. F. Mano, M. E. Gomes, A. P. Marques, and H. S. Azevedo, Eds., pp. 644-679, Woodhead Publishing, Cambridge, UK, 2008. 


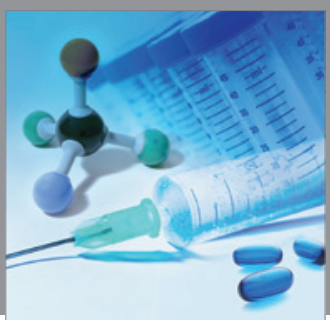

International Journal of

Medicinal Chemistry

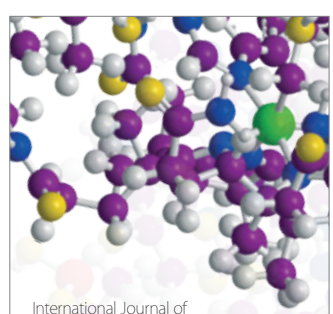

Carbohydrate Chemistry

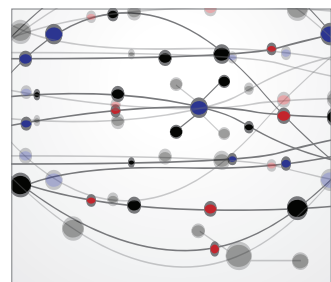

The Scientific World Journal
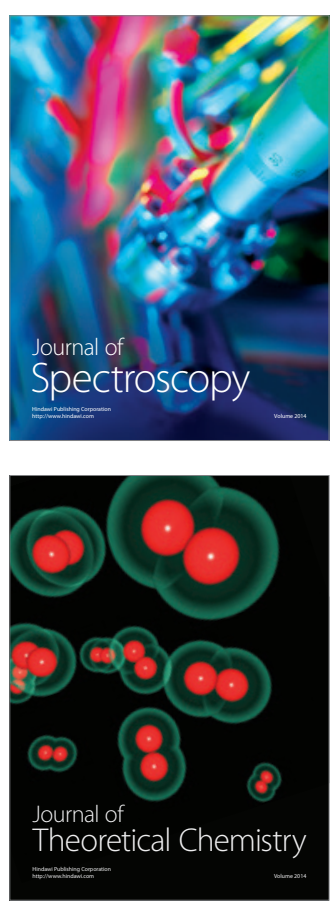
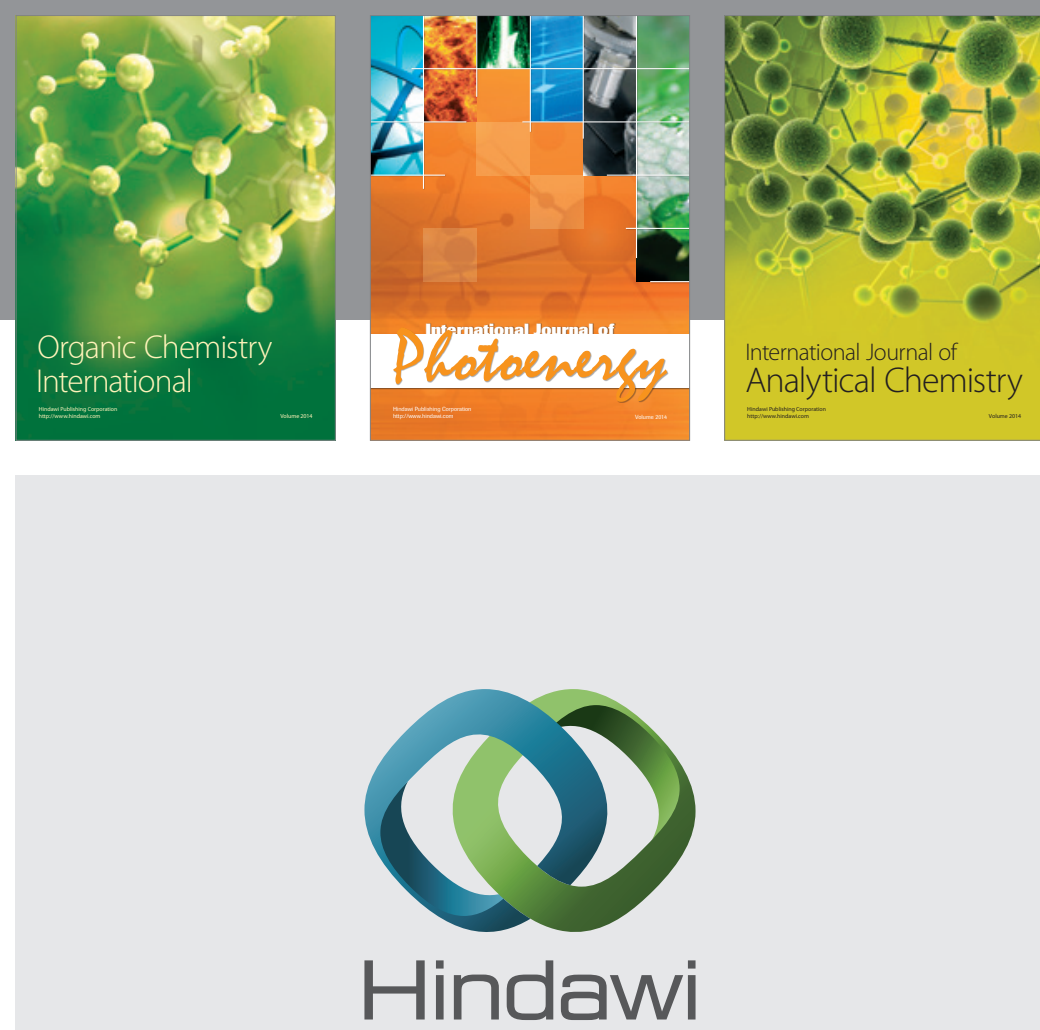

Submit your manuscripts at

http://www.hindawi.com
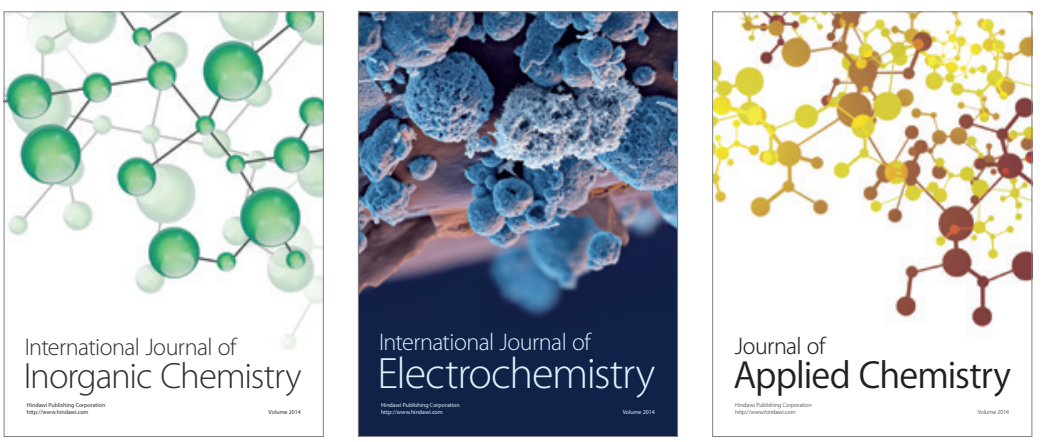

Journal of

Applied Chemistry
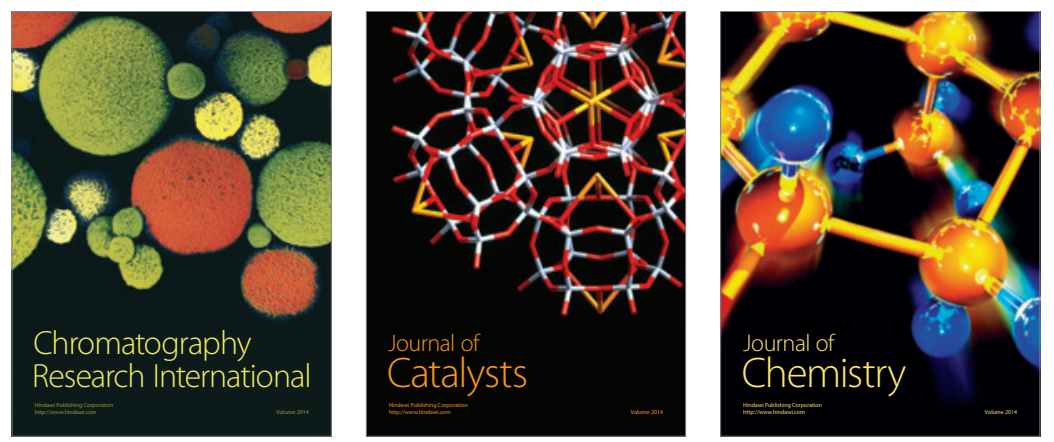
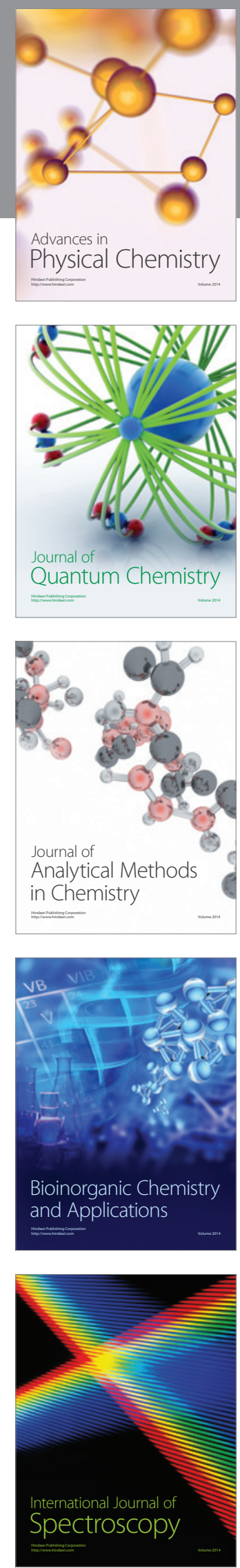